Plant Tissue Cult. \& Biotech. 30(1): 57-63, 2020 (June)

(C)Bangladesh Assoc. for Plant Tissue Culture \& Biotechnology

$\overline{\text { PTC\&B }}$

\title{
In vitro Micropropagation of Bacopa monnieri (L.) Penn. - An Important Medicinal Plant
}

\section{Md. Adnan Rahe ${ }^{1}$, Sanjida Rahman Mollika', M. Salim Khan, Tanjina Akhtar Banu, G. M. Al Amin', Md. Ahsan Habib, Shahina Akter, Mousona Islam and Ripa Akter Sharmin ${ }^{1^{*}}$}

Plant Tissue Culture Section, Bangladesh Council of Scientific and Industrial Research, Dhanmondi, Dhaka-1205, Bangladesh

Key words: Regeneration, Bacopa monnieri, Leaf, Node

\begin{abstract}
Investigation on in vitro multiple shoot regeneration in Bacopa monnieri (L.) Penn. using leaf and nodal explants was carried out on MS containing various concentrations and combinations of BAP, Kn, NAA and 2,4-D. Of the two explants, leaf showed the best response towards shoot regeneration and subsequent plant development on MS with 1.0 $\mathrm{mg} / \mathrm{BAP}$ and $0.25 \mathrm{mg} / \mathrm{Kn}$. In this combination, the mean number of shoots/explant was $10.6 \pm 0.11$ in leaf and $9.6 \pm 0.29$ in nodal explants. Maximum shoot length was recorded as $12.6 \pm 0.21$ and $11.20 \pm 0.30$ from leaf and nodal explants after six weeks of culture, respectively. Half strength of MS supplemented with $0.25 \mathrm{mg} / \mathrm{IBA}$ was found to be the best medium for root formation. The in vitro regenerated plantlets were successfully transplanted in soil after acclimatization.
\end{abstract}

\section{Introduction}

Medicinal plants have long been used for the purpose of health care throughout the world since ancient times by Ayurvedic, Unani and folk medicinal systems for its powerful medicinal properties (Islam et al. 2017). Bacopa monnieri (L.) Penn. commonly known as "Brahmi Shak" is an important medicinal herb belongs to the family Plantaginaceae. This herb is used for the preparation of brain tonic primarily for nerve system, to treat insomnia and nervous debility. The plant has anticancer, antioxidant, memory-enhancing, and cardio-tonic properties (Mathur et al. 2002). It can enhance immune function by increasing immunoglobulin production. It may regulate antibody production by augmenting both Th1 and Th2 cytokine production (Yamada et al. 2011).

*Author for correspondence: <ripa.sharmin@gmail.com>. ${ }^{1}$ Department of Botany, Jagannath University, Dhaka-1100, Bangladesh.

DOI: https://doi.org/10.3329/ptcb.v30i1.47791 
So far B. monnieri has been studied extensively for its high medicinal values and prized chemical constituents, of which are present alkaloids brahmine and herpestine and among the principle active factors reported are saponins, monnierin, hersaponin, bacoside A and bacoside B and Dammarene-type triterpenoid saponins (Mathur et al. 2002).

Most of the medicinal plants, even today are collected from their wild habitats. Secondly, there are many reasons for its depletion in nature all over the world. Long time ago the IUCN already listed B. monnieri as a threatened species. The natural regeneration of this herb is hampered by death of seedlings at two- leaf stage and specific habitat (marshy areas) requirements. Seed viability is poor so raising plants from seeds is a difficult task. Vegetative propagation by stem cutting is also a slow process. Besides, it is observed that the growth of Bacopa species is dependent on seasonal changes. Thus, conventional method of propagation is not adequate to meet the demand of Bacopa raw materials for its use in medicine and industry.

The continued commercial exploitation of medicinal plants has resulted in reduction of the population of many species in their natural habitat. It is important to conserve this medicinal plant through different techniques. Plant tissue culture remains one of the most basic biotechnological techniques with its varied and vast applications. Plant cell cultures have emerged as new alternatives for the production of secondary metabolites (Rao and Ravishankar 2002). The rapidity of multiplication of true-to-type plants and efficient transplantation of $B$. monnieri can be useful in conservation and propagation of elite plants for commercial exploitation. So a suitable in vitro regeneration protocol is needed for the mass multiplication under various conditions and its conservation. In addition, the production of secondary metabolites through field cultivation of plants has various disadvantages such as low yields and variations in the amounts produced due to geographical, seasonal, and environmental conditions (Jain et al. 2013). There is a need to develop alternative methods to produce bacosides for the pharmaceutical industryand to conserve the plant. The tissue culture technique can be further utilized for the genetic modification of the germ line followed by micropropagation to obtain good number of new plants with desired properties (Bagherieh-Najjar and Nezamdoost 2016). So, the main objective of the present investigation was to develop a rapid and efficient protocol for a large scale in vitro micropropagation of B. monnieri (L.) Penn.

\section{Materials and Methods}

Plant materials Bacopa monnieri (L.) Penn. were collected from field grown plants of the medicinal plant garden of BCSIR. Leaves and nodal explants were washed under running tap water for $20 \mathrm{~min}$. Then the explants were washed with detergent, under running tap water until the detergent washed out completely. The explants were then sterilized by $20 \%$ Savlon, followed by $0.1 \%$ of Tween- 20 for $2 \mathrm{~min}$ and washed with water thoroughly. Sterilization was then done by $70 \%$ alcohol for $30 \mathrm{sec}$ followed by washing 
three times with distilled water. After transferring the explants in autoclaved flask, final surface sterilization was done with $0.1 \% \mathrm{HgCl}_{2}$ solution for $2 \mathrm{~min} 30 \mathrm{sec}$ inside the laminar flow cabinet. During this period, the flask was agitated. Then the explants were washed five times with sterilized distilled water.

Surface sterilized leaf and nodal explants were then inoculated on MS containing various PGRs supplements singly or in combinations for callus induction and shoot regeneration. These cultures were maintained at $25 \pm 2^{\circ} \mathrm{C}$ with a photoperiod $16 / 8 \mathrm{hrs}$ light and dark per day. Cultures were sub-cultured regularly, at an interval of 21-28 days for multiple shoot regeneration in the fresh media. About 2.0-3.0 cm long shoots were separated and cultured on freshly prepared rooting medium containing full and half strengths of MS without PGRs or with different concentrations and combinations IBA for root induction. The plantlets with sufficient number of roots were taken out from the culture vessels and cleaned the agar on root surface under running tap water. The plantlets were then transplanted to small pots containing sterilized soil for further development.

\section{Results and Discussion}

The work on regeneration was mainly conducted using the leaf and nodal explants from Bacopa monnieri (L.) Penn. Of the two explants, leaf was found to be the most responsive in terms of percentage of shoot regeneration as well as the number of shoots per explants (Table 1). The age of the explants is very important for in vitro regeneration. Physiologically younger tissue is generally much more responsive. In many cases, older tissue will not form callus that is incapable of regeneration. In addition, younger tissue is generally easier to surface disinfect and establish clean cultures. It was also found that around middle aged explants were suitable for callus induction and in vitro regeneration of shoots. MS supplemented with various concentrations of BAP, Kn, NAA and 2,4-D singly or in combinations were used for both direct and indirect shoot regeneration. Leaf explants produced maximum number of shoots compared to those produced from another explants. Joshi et al. (2010) showed that leaf explants were better for in vitro regeneration in Bacopa species.

Effectiveness of MS for development of multiple shoots in different plant species have already been reported by previous workers (Gorge et al. 2007, Shrivastava et al. 2008). Shoots were directly regenerated from leaf explants on MS with $2.0 \mathrm{mg} / \mathrm{BAP}$ and the number of shoots per explants was very low. Tiwari et al. (2001) reported that MS supplemented with BAP showed best response in case of node, internode and leaf explants. Maximum number of shoots per explants was observed when the explants were cultured on MS with $0.5 \mathrm{mg} / \mathrm{BAP}$. On the otherhand the mean number of shoot per explants decreased in increased concentrations of BAP. So, BAP alone was not effective for multiple shoot formation of Bacopa monnieri. Praveen et al. (2009) reported the use of various plant growth regulators viz., BAP, Kn and TDZ and Kamonwannasit et al. (2008) 
used 6-benzyleadenine, thidiazuron and chitosan for the enhancement of biomass and bacoside content in Brahmi. Pandiyan and Selvaraj (2012) showed that $1.0 \mathrm{mg} / \mathrm{BAP}, 1.0$ $\mathrm{mg} / \mathrm{Kn}$ and $1.0 \mathrm{mg} / \mathrm{NAA}$ was most effective for obtaining maximum number $(18.4 \pm 0.8)$ of shoots from nodal explants.

Table 1. Effect of MS supplemented with different concentrations and combinations of BAP, $\mathrm{Kn}$, NAA and 2,4-D on shoot regeneration from leaf and nodal explants of B. monnieri.

\begin{tabular}{|c|c|c|c|c|c|c|c|c|}
\hline Explants & $\begin{array}{l}\text { BAP } \\
(\mathrm{mg} /)\end{array}$ & $\begin{array}{l}\mathrm{Kn} \\
(\mathrm{mg} /)\end{array}$ & $\begin{array}{l}\text { NAA } \\
(\mathrm{mg} /)\end{array}$ & $\begin{array}{l}2,4-\mathrm{D} \\
(\mathrm{mg} \Lambda)\end{array}$ & $\begin{array}{l}\% \text { of } \\
\text { responsive } \\
\text { explants }\end{array}$ & $\begin{array}{l}\text { Days } \\
\text { required } \\
\text { for shoot } \\
\text { initiation }\end{array}$ & $\begin{array}{l}\text { Mean no. of } \\
\text { shoots /explants } \\
\text { after } 45 \text { days of } \\
\text { culture } \\
( \pm \text { SE })\end{array}$ & $\begin{array}{l}\text { Mean } \\
\text { length }(\mathrm{cm}) \text { of } \\
\text { shoots/explant } \\
\text { after } 45 \text { days of } \\
\text { culture }( \pm \mathrm{SE})\end{array}$ \\
\hline \multirow{8}{*}{ Leaf } & 0.5 & - & - & - & 70 & $18-20$ & $4.0 \pm 0.65$ & $3.4 \pm 0.12$ \\
\hline & 0.5 & - & - & 0.2 & 80 & $18-20$ & $5.63 \pm 0.72$ & $4.82 \pm 0.72$ \\
\hline & 0.5 & - & - & 0.5 & 85 & $16-18$ & $6.8 \pm 0.33$ & $8.65 \pm 0.83$ \\
\hline & 1.0 & 0.25 & - & - & 95 & $13-15$ & $10.6 \pm 0.11$ & $12.6 \pm 0.21$ \\
\hline & 1.0 & 0.50 & - & - & 85 & $14-16$ & $8.8 \pm 0.13$ & $10.40 \pm 0.22$ \\
\hline & 1.0 & - & 0.2 & - & 95 & $13-15$ & $7.2 \pm 0.32$ & $9.50 \pm 0.42$ \\
\hline & 1.0 & - & 0.5 & & 85 & $15-17$ & $7.29 \pm 0.47$ & $7.29 \pm 0.47$ \\
\hline & 2.0 & - & - & - & 65 & $18-20$ & $3.0 \pm 0.45$ & $3.5 \pm 0.67$ \\
\hline \multirow{8}{*}{ Node } & 0.5 & - & - & - & - & - & $3.8 \pm 0.26$ & $3.66 \pm 0.77$ \\
\hline & 0.5 & - & - & 0.2 & 80 & $17-20$ & $4.13 \pm 0.62$ & $4.13 \pm 0.62$ \\
\hline & 0.5 & - & - & 0.5 & 85 & $16-18$ & $6.4 \pm 0.53$ & $8.5 \pm 0.63$ \\
\hline & 1.0 & 0.25 & - & - & 95 & $15-16$ & $9.6 \pm 0.29$ & $11.20 \pm 0.30$ \\
\hline & 1.0 & 0.50 & - & - & 75 & $15-16$ & $7.4 \pm 0.41$ & $10.20 \pm 0.23$ \\
\hline & 1.0 & - & 0.2 & - & 95 & $15-16$ & $6.4 \pm 0.22$ & $9.00 \pm 0.11$ \\
\hline & 1.0 & - & 0.5 & - & 90 & $15-17$ & $6.72 \pm 0.49$ & $6.72 \pm 0.49$ \\
\hline & 2.0 & - & - & - & 60 & $18-20$ & $3.1 \pm 0.91$ & $3.6 \pm 0.85$ \\
\hline
\end{tabular}

MS supplemented with $1.0 \mathrm{mg} / \mathrm{BAP}$ and $0.25 \mathrm{mg} \Lambda \mathrm{Kn}$ was found to be most effective for in vitro regeneration of shoots from the callus of leaf and nodal explants. Light green callus formed within 13-15 days of inoculation in leaf explants (Fig. 1a) whereas it took about 15-16 days in nodal segments explants. In this combination, the percentage of responsive explants was $95 \%$ in both explants. The regenerated shoots were transferred to fresh medium for shoot elongation. Fig. $1 \mathrm{~b}$ shows the formation of multiple shoots from nodal explants. In case of leaf and nodal explants, mean number of shoots per explant was 10.6 \pm 0.11 and 9.6 \pm 0.29 ,respectively (Table 1 and Fig. 1c-e). Fig. If represents the formation of elongated shoots regenerated from nodal explants. Gurnani 
et al. (2012) used MS with BAP and NAA for production of multiple shoots. Mohapatra and Rath (2005) also reported maximum shoot multiplication on MS supplemented with BAP and NAA. In the present investigation, multiple shoot regeneration was also observed on MS with $1.0 \mathrm{mg} / \mathrm{BAP}$ and $0.2 \mathrm{mg} / \mathrm{NAA}$. It has been observed that six weeks after culture, the mean number of shoot was $7.2 \pm 0.32$ in leaf explants whereas, in case of nodal explants it was $6.4 \pm 0.22$.

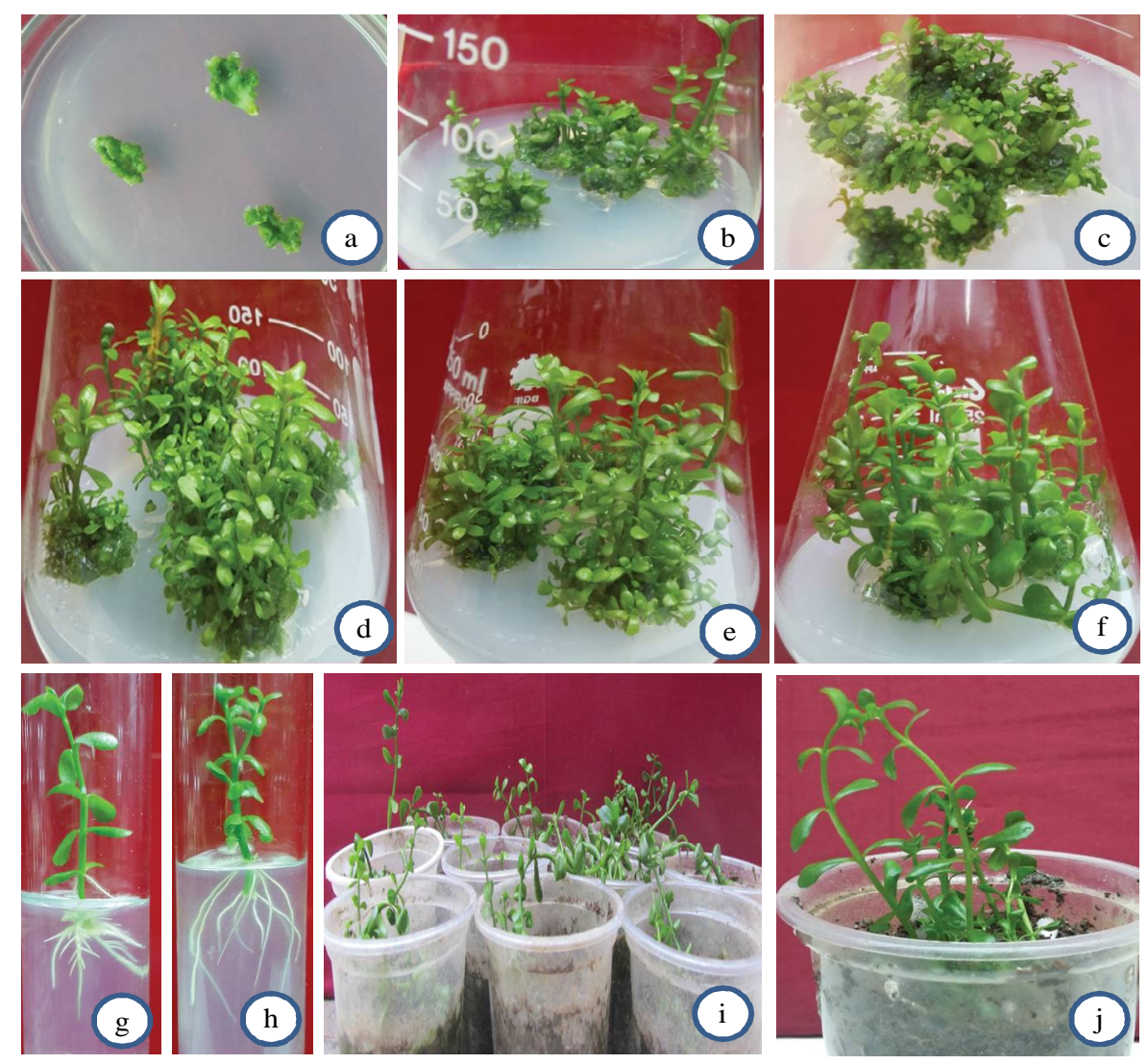

Fig. 1. Different stages of in vitro regeneration of Bacopa monnieri from leaf and nodal explants. (a) Initiation of callus from leaf explants within 8 - 10 days on MS with $1.0 \mathrm{mg} / \mathrm{BAP}$ and $0.25 \mathrm{mg} / \mathrm{Kn}$, (b) formation of shoot from the green compact callus of nodal explants within 15 -16 days on same media, (c) initiation of multiple shoot from leaf callus on same medium, (d) Multiple shoots formation from callus of leaf on same medium, (e) elongated multiple shoots regenerated from callus of leaf after six weeks on same media, (f) elongated multiple shoots regenerated from callus of nodal segments after six weeks on same media, $(\mathrm{g})$ initiation of roots from the base of excised regenerated shoot within 10-15 days on half strength of MS with $0.25 \mathrm{mg} / \mathrm{IBA}$, (h) formation of multiple roots on same medium and (i,j) regenerated plantlets on soil containing small plastic pots.

Multiple shoots were also obtained on MS with $0.5 \mathrm{mg} / \mathrm{BAP}$ and $0.5 \mathrm{mg} / 2$, 4-D from leaf and nodal explants. From the Table 1 it is observed that both the explants showed more or less similar response towards days required for shoot initiation and percentage of 
responsive explants. After 16-18 days of culture initiation of shoots from callus was observed from both the explants. Maximum shoot length after six weeks of culture from leaf explants was $8.65 \pm 0.83$. In this combination, the mean number of shoot was $6.8 \pm 0.33$ in leaf explants and incase of node it was $6.4 \pm 0.53$. In vitro regeneration via callus induction was carried out on MS with 2,4-D (0.5 mg 1 ) by using leaf explants (Kharde et al. 2018).

Table 2. Effect of half strength of MS supplemented with different concentrations of IBA on root induction from the in vitro regenerated shoots.

\begin{tabular}{lcccc}
\hline $\begin{array}{l}\text { IBA } \\
(\mathrm{mg} \Lambda)\end{array}$ & $\begin{array}{l}\text { Days required } \\
\text { for root initiation }\end{array}$ & $\begin{array}{l}\text { \% of responsive } \\
\text { explants }\end{array}$ & $\begin{array}{l}\text { Mean no. of } \\
\text { roots /plant }( \pm \mathrm{SE})\end{array}$ & $\begin{array}{l}\text { Mean length }(\mathrm{cm}) \text { of } \\
\text { roots } / \text { plant }( \pm \mathrm{SE})\end{array}$ \\
\hline 0.1 & $10-15$ & 100 & $7.5 \pm 0.18$ & $2.5 \pm 0.22$ \\
0.2 & $10-15$ & 100 & $10.6 \pm 0.32$ & $3.1 \pm 0.15$ \\
0.25 & $10-15$ & 100 & $14.0 \pm 0.23$ & $3.7 \pm 0.21$ \\
0.5 & $10-15$ & 70 & $6.1 \pm 0.28$ & $1.6 \pm 0.25$ \\
\hline
\end{tabular}

Root induction has also been reported in Bacopa using MS supplemented with $1.0 \mathrm{mg} /$ IAA and $1.0 \mathrm{mg} /$ IBA (Tiwari et al. 2001). Narayan et al. (2011) found maximum number and length of roots with IBA and IAA. Showkat et al. (2010) reported that MS solidified with $7 \mathrm{~g} \Lambda$ of agar along with sugar $20 \mathrm{~g} \Lambda$ was better for root induction. In the present study, regenerated shoots were cultured on both half and full strength of MS with or without different concentrations of IBA (0.1-0.5 $\mathrm{mg} /)$. In this case half strength of MS supplemented with $0.25 \mathrm{mg} A$ IBA found to be best for the initiation of root from the base of in vitro grown shoots (Fig. 1g-h). Here mean number of roots per explants was $14 \pm 0.23$. After sufficient development of roots, plantlets were successfully transplanted into small plastic pots (Fig. 1i-j). Three weeks after transplantation, when the regenerated plants were fully established in the small pots, then they were transferred to larger pots for further growth and development. The survival rate of plantlets was $90 \%$.

On the basis of the above discussion it may be concluded that regeneration protocol developed in the present investigation can successfully be used for large scale clonal propagation of Bacopa monnieri. This will reduce the pressure on natural population of this valuable medicinal plant species and thus be indirectly useful for conservation of this plant species.

\section{References}

Bagherieh-Najjar M and Nezamdoost T (2016) Optimization of shikonin production in Onosma dichroantha callus using response surface methodology. Plant Cell Tiss. Org. Cult. 126: 399-409.

Gorge S, Geetha SP, Raja SS, Balachandran I and Ravindran PN (2007) In vitro medium-term conservation of Bacopa monnieri (L.) Penn. -The memory plus plant under slow growth conditions. Plant Genet. Resour. Newsl. 151: 49-55.

Gurnani C, Kumar V, Mukhija S, Dhingra A, Rajpurohit S and Narula P (2012) In vitro regeneration of brahmi (Bacopa monnieri (L.) Penn.) - A threatened medicinal plant. Kathmandu Univ. J. Sci. Eng. and Tech. 8(1): 97-99. 
Islam ATMR, Islam MM and Alam MF (2017) Rapid in vitro clonal propagation o of herbal spice, Mentha piperita L. using shoot tip and nodal explants. J. Res. Plant Sci. 5(1): 43-50.

Jain M, Rajput R and Mishra A (2013) Enhancement of secondary metabolite biosynthesis in Bacopa monnieri: An in vitro study. Res. J. Rec. Sci. 2(1): 13-16.

Joshi AG, Pathak AR, Sharma AM and Singh S (2010) High frequency of shoot regeneration on leaf explants of Bacopa monnieri. Environ. Exp. Biol. 8: 81-84.

Kamonwannasit S, Phrompittayarat W, Ingkaninan K, Tanaka H and Putalun W (2008) Improvement of pseudojujubogenin glycosides production from regenerated Bacopa monnieri (L.) Wettstand enhanced yield by elicitors. Z. Naturforsch. 63: 879-83.

Kharde AV, Kore SV and Khetmalas MB (2018) Elicitation of bacoside content using plant growth regulators in cell suspension culture of Bacopa monnieri (L.) Wettst. Plant Tiss. Cult. Biotech. 28(2): 191-199.

Mathur S, Gupta MM, Ram M, Sharma S and Kumar S (2002) Herb yield and bacoside-A content of field grown Bacopa monnieri accessions. J. Herbs Spices Med. Plants 9: 11-18.

Mohapatra HP and Rath SP (2005) In vitro studies of Bacopa monnieri- an important medicinal plant with reference to its biochemical variations. Indian J. Exp. Biol. 43(4): 373-376.

Narayan TB, Khatri P, Julfikar A and Srivastava A (2011) Tissue culture of endangered brahmi (Bacopa monnieri) (Linn) family Scrophulariaceae. J. Pharmaco. Herbal Formul. 1(4): 73-84.

Pandiyan P and Selvaraj T (2012) In vitro multiplication of Bacopa monnieri (L.) Pennell from shoot tip and nodal explants. J. Agric. Tech. 8(3): 1099-1108.

Praveen N, Naik PM, Manohar SH, Nayeem A and Murthy HN (2009) In vitro regeneration of brahmi shoots using semisolid and liquid cultures and quantitative analysis of bacoside A. Acta Physiol. Plant.31(4): 723-728.

Rao RS and Ravishankar GA (2002) Plant cell cultures: Chemical factories of secondary metabolites. Biotechnol. Adv. 20:101-153.

Showkat P, Zaidi Y, Asghar S and Jamaluddin S (2010) In vitro propagation and callus formation of Bacopa monnieri (L.) Penn. Plant Tissue Cult. Biotech. 20(2): 119-125.

Shrivastava R, Banjaree S, Jehnichen D, Voit B and Bohme F (2008) In situ preparation of polyimide composites based on functionalized carbon nanotubes. Macromol. Mater. Eng. 294(2): 96-102.

Tiwari V, Tiwari KN and Singh BD (2001) Comparative studies of cytokinins on in vitro propagation of Bacopa monnieri. Plant Cell Tiss. Org. Cult. 66: 9-16.

Yamada K, Hung P, Park TK, Park PJ and Limb BO 2011. A comparison of the immune stimulatory effects of the medicinal herbs Echinacea, Ashwagandha and Brahmi. J. Ethnopharmacol. 137(1): 231-235.

(Manuscript received on 31 March, 2020; revised on 26 May, 2020) 